\begin{tabular}{|c|c|}
\hline 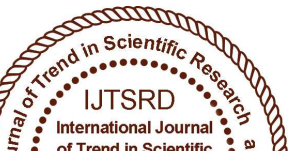 & $\begin{array}{l}\text { International Journal of Trend in Scientific } \\
\text { Research and Development (IJTSRD) }\end{array}$ \\
\hline $\begin{array}{lll} & \\
0\end{array}$ & International Open Access Journal \\
\hline 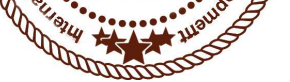 & ISSN No: $2456-6470 \mid$ www.ijtsrd.com | Volume - 2 | Issue -4 \\
\hline
\end{tabular}

\title{
CFD Analysis of Heat Transfer Enhancement in Shell and Tube Type Heat Exchanger creating Triangular Fin on the Tubes
}

\author{
Sudhanshu Pathak ${ }^{1}$, H. S. Sahu ${ }^{2}$ \\ ${ }^{1}$ M.Tech Scholar, ${ }^{2}$ Assistant Professor \\ Millennium Institute of Technology, Bhopal, Madhya Pradesh, India
}

\begin{abstract}
Shell and Tube heat exchangers are having special importance in boilers, oil coolers, condensers, preheaters. Shell and Tube heat exchanger is one such heat exchanger, provides more area for heat transfer between two fluids in comparison with other type of heat exchanger. To intensify heat transfer with minimum pumping power innovative heat transfer fluids called Nano fluids have become the major area of research now a days.
\end{abstract}

The primary aim is to evaluate the effect of different weight concentration and temperatures on convective heat transfer. Increasing the weight concentration and temperatures leads to enhancement of convective heat transfer coefficient. In the present, work attempts are made to enhance the heat transfer rate in shell and tube heat exchangers. A multi pass shell and tube heat exchanger with 3 tubes with fins modelling is done using ANSYS. Nanofluid such as A12O3-H2O is used. The CFD simulated results achieved from the use of the creating fin in tube side in shell and tube type heat exchanger are compared with without fin. Based on the results, providing fins on tube causes the increment of overall heat transfer coefficient which results in the enhancement of heat transfer rate of heat exchanger.

Keywords: Shell and Tube heat exchanger, Nano fluids, Heat transfer, ANSYS 14.5, Overall heat transfer coefficient, extended surface

\section{INTRODUCTION}

Heat exchanger is defined as a device which is use to transfer energy between two fluids which are at different temperature with maximum rate and minimum cost.

Classification of Heat Exchanger: There are many types of heat exchanger which are widely used in industry and application of power generation. Heat exchanger is classified based on following criteria:

- According to flow arrangements of fluids.

- According to heat transfer process.

- 1 According to geometry of construction.

\section{a) According to flow arrangement of fluids}

A heat exchanger can have several different flow patterns. Counter flow, parallel flow, and cross flow are common heat exchanger types. A counter flow heat exchanger is the most efficient flow pattern of the three. It leads to the lowest required heat exchanger surface area because the logarithmic mean temperature drop is the highest for a counter flow heat exchanger.

\section{i) Parallel flow heat exchanger}

A double pipe heat exchanger can be operated in parallel flow mode. Similarly a shell and tube heat exchanger can be operated in approximately parallel flow by having both fluids enter at one end and exit at the other end. With parallel flow the temperature difference between the two fluids is large at the entrance end, but it becomes small at the exit end as the two fluid temperatures approach each other. The overall measure of heat transfer driving force, the logarithmic mean temperature difference is greater for counter flow, and so the heat exchanger surface area 
requirement will be larger than for a counter flow heat exchanger with the same inlet and outlet temperatures for the hot and the cold fluid.

\section{ii) Counter flow heat exchanger}

A counter flow heat exchanger has the hot fluid entering at one end of the heat exchanger flow path and the cold fluid entering at the other end of the flow path. Counter flow is the most common type of liquidliquid heat exchanger, because it is the most efficient. A double pipe heat exchanger is usually operated as a counter flow heat exchanger

\section{iii) Cross flow heat exchanger}

A car radiator and an air conditioner evaporator coil are examples of cross flow heat exchangers. In both cases heat transfer is taking place between a liquid flowing inside a tube or tubes and air flowing past the tubes. With a car radiator, the hot water in the tubes is being cooled by air flowing through the radiator between the tubes. With an air conditioner evaporator coil, air flowing past the evaporator coils is cooled by the cold refrigerant flowing inside the tubes of the coil. Cross flow heat exchangers are typically used for heat transfer between a gas and a liquid.

\section{LITERATURE REVIEW}

Heat transfer performance of heat exchangers can be improved by using nanofluids. The nanofluids can help to reduce the cost and size of the heat exchangers, and heating and cooling systems. Nano fluids are study of behaviour of fluids, which are confined to Nano meter sized structure of particles. Nano fluids are plays an important role in heat transfer applications. Many industrial processes involve the transfer of heat. Heating or cooling in an industrial application may create savings heat energy, reducing time and increasing life of working equipment like heat exchangers, boilers and radiators etc. In this work Shell and tube Heat exchanger is used to estimate the heat transfer rate. There is a lot of research going on in this area, a few of them are stated below,

Yannar et al.(2008): Investigated the flow and heat transfer characteristic of spiral pipe heat exchanger using different type of Nano fluid with different concentration such as $\mathrm{Al}_{2} \mathrm{O}_{3}$-water, $\mathrm{TiO}_{2}$-water, $\mathrm{CuO}$ water Nano fluid with $1 \%, 1 \%$ and $3 \%$ concentration respectively. Test section made of copper tube had the ratio of pitch per diameter is 7 , mean hydraulic diameter is $30 \mathrm{~mm}, 10 \mathrm{~mm}$ diameter and $1600 \mathrm{~mm}$ length. Heat transfer enhanced $28 \%$ at $0.8 \%$ concentration of nano fluid, due to high concentration shear stress of Nano fluid is increased. Heat transfer enhancement is high in spiral pipe compared with circular pipe, because the pressure drop is high in spiral pipe. Heat transfer co efficient is decreases when axial distance of Nano fluid is increasing, because formation of boundary layer.

Manna et al.(2014): Investigated the thermal conductivity enhancement of SiC-water Nano fluid using transient hot wire device. Thermal conductivity of Nano fluid is increased with increasing the concentration of nanoparticle, $26 \%$ of maximum thermal conductivity is obtained when using $0.8 \%$ concentration of Nano fluid. Mechanically milled nanoparticles having high heat transfer enhancement. Nanoparticle volume and shape is important factor to enhance the thermal conductivity of Nano fluid, at $27 \mathrm{~nm}$ sized nanoparticle enhanced $12 \%$ of thermal conductivity Nano fluid.

Shriram S. Sonawan et e al.(2015): Investigated the heat transfer characteristics of $\mathrm{Al}_{2} \mathrm{O}_{3}-$ water nanofluids as a coolant used in concentric tube heat exchanger. The heat exchanger is fabricated from copper concentric inner tube with a length of 1000 $\mathrm{mm}$. The nanofluids are the mixture of water as base fluid and $\mathrm{Al}_{2} \mathrm{O}_{3}$ particles in Nano range. The results obtained from the nanofluids cooling in concentric tube heat exchanger are compared with those from base fluids. The effects of inlet flow rate of hot fluids, Reynolds's number and composition of nanofluids on concentric tube heat exchanger are considered. It is observed that average heat transfer rates for nanofluids as cooling media are higher than those for the water as cooling media, and this increases with concentration of nanofluids' composition. The results of this study have technological importance for the efficient design of concentric tube heat exchanger to enhance cooling performance at low heat flux cooling systems

Khorasani et al. (2017): There was no work found which considered cumulative effect of nanofluids and fins on shell and tube heat exchanger in terms of overall heat transfer coefficient and net heat transferred.

K.Somasekhar et al.(2018):In this study a multi pass shell and tube heat exchanger with 3 tubes modeling is done using CATIA and meshing has done using 
ICEM CFD software, simulations has done by using CFD-FLUENT software. Using Fluent, computational fluid dynamics software the pressure drop, heat transfer characteristics of $\mathrm{Al}_{2} \mathrm{O}_{3}$-water nanofluid, and Distilled water are analyzed under turbulent flow condition. Nanofluid such as $\mathrm{Al}_{2} \mathrm{O}_{3}-\mathrm{H}_{2} \mathrm{O}$ is used as cooling medium instead of Distilled water. Finally the CFD simulated results are compared with experimental results. The effects of Peclet number, volume concentration of suspended nanoparticles, and particle type on the heat transfer characteristics were investigated. Based on the results, adding of nanoparticles to the base fluid (Distilled water) causes the significant enhancement of heat transfer characteristics.

\section{PROBLEMS FORMULATION}

From the previous works further problems are identified. For enhancement of the heat transfer, the factors which affect the heat transfer rate are area contact, turbulence creating on fluid flow and Thermophysical properties of fluid. In the previous finding researches, heat transfer rate is low due to the low value of overall heat transfer coefficient and Nusselt number.

\section{RESEARCH OBJECTIVES}

It can be observed from the problems identification dissolving by the improvement in the shell and tube type heat exchanger by applying various techniques which causes the result in the enhancement of heat transfer rate in the heat exchanger. The effort make to enhancement of heat transfer in heat exchanger are develop a proper Heat Exchanger for maximum heat transfer rate.

\section{METHODOLOGY}

In this study a CFD model has design in Design modular using ANSYS 14.5. The shell and tube heat exchanger consists of the components Shell and tubes.

Table 1 Specification of Shell and Tube

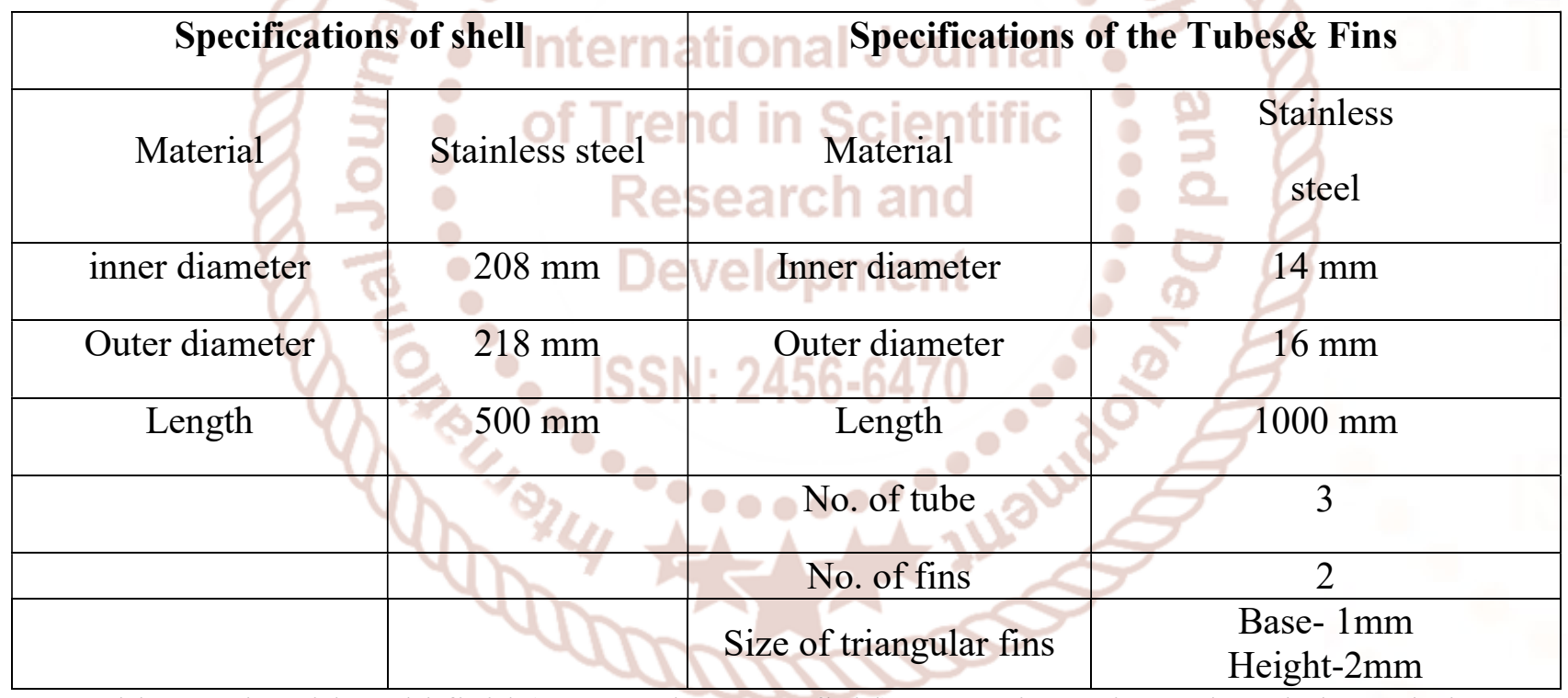

Table 2 Tube Side cold fluid (Water- $\mathrm{Al}_{2} \mathrm{O}_{3}$ nanofluid) Properties Using Pak and cho Relation

In this work the model of shell and tube type heat exchanger are modeled in design modular. The tube used is the $\mathrm{U}$ tube type with triangular fin whose dimension is shown in the above chapter. The meshing has been done in the ICEM Meshing method and the solver used for the simulation is CFD. The model of Heat Exchanger is shown in the figure 1. 


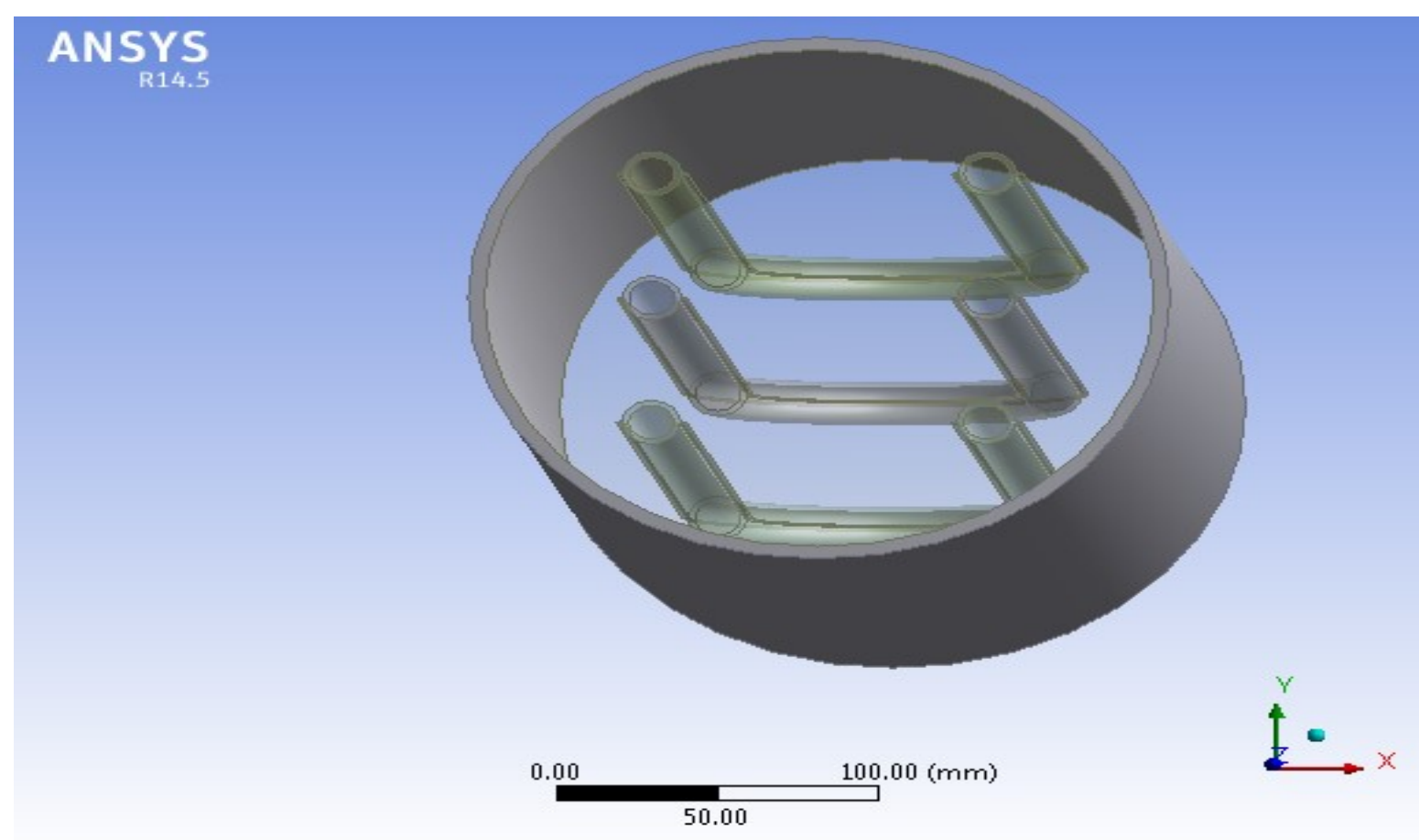

Fig. 1 Geometry model of shell and tube heat exchanger

The Designed model of Heat Exchanger is meshed in ICEM CFD Meshing. The meshing type has done quardcore and tetrahedral. The number of nodes and elements that are used are473198 and 2097041 respectively.

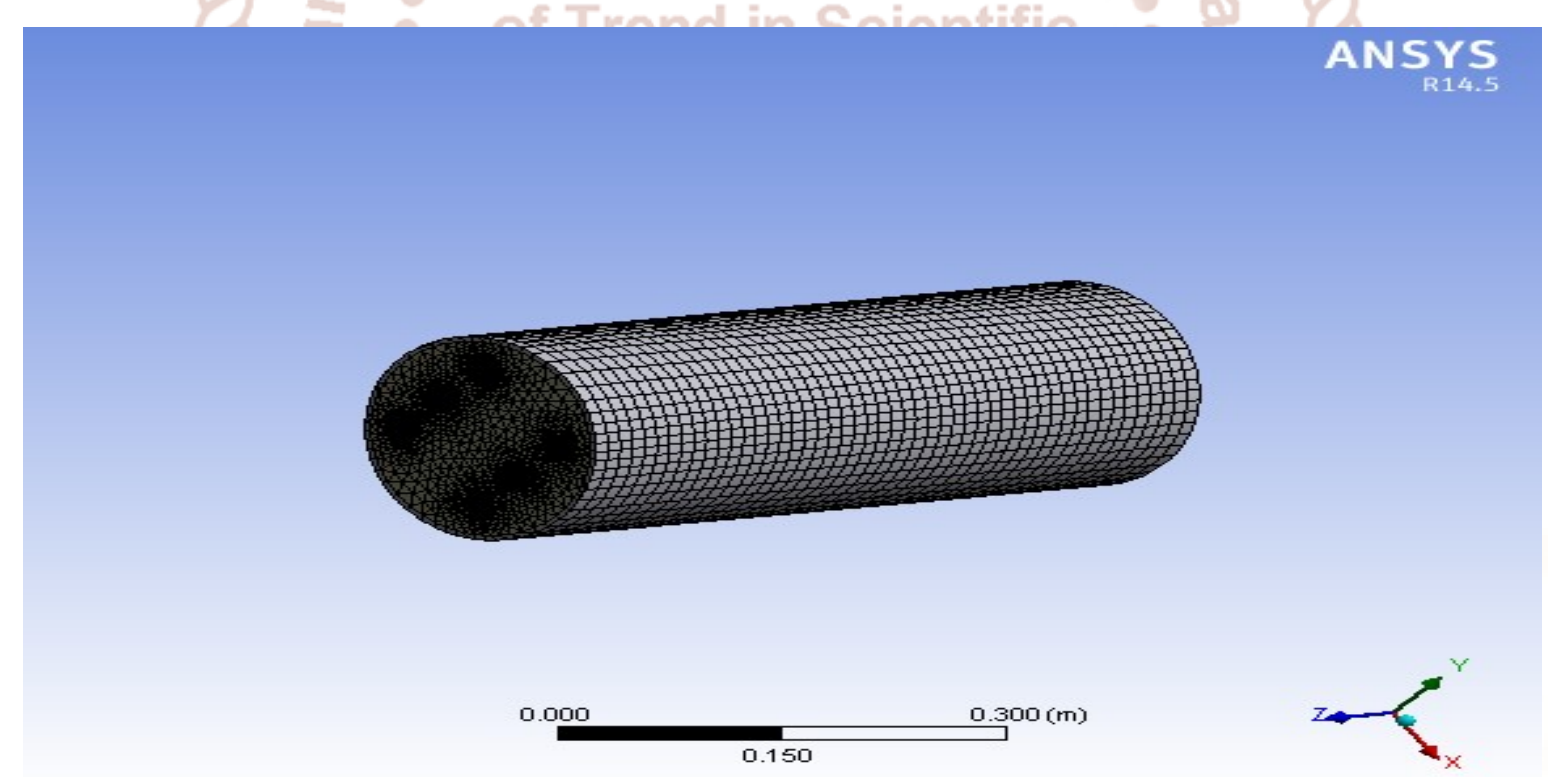

Fig. 2 Meshing model of shell and tube Heat Exchanger

Name Selection: A different part of the heat exchanger and fluid flowing inside the heat exchanger is selected and the names are given to them so that boundary conditions can be applied on different boundary. 


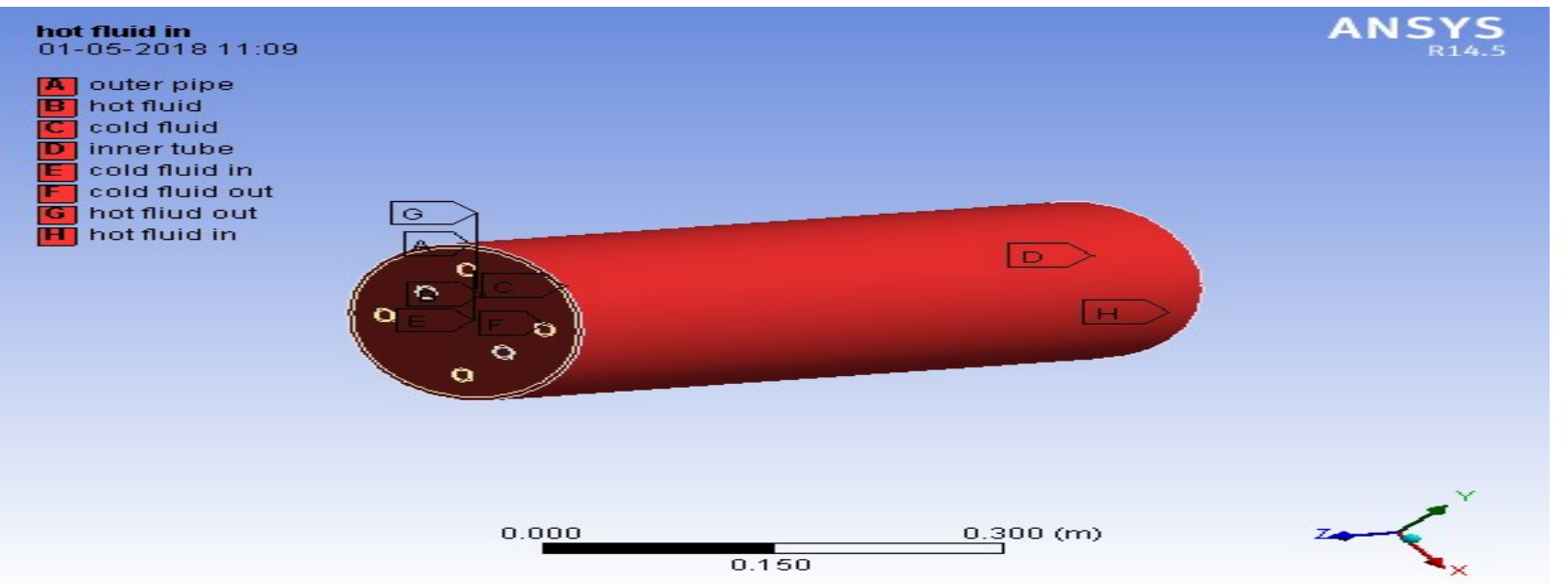

Fig. 3 Name Selection of shell and tube Heat Exchanger

Model Selection: In model selection only three parameters are selected. Remaining parameter are remained as Default. The three parameters are:-Eulerian, Energy - on and - Standard k-e turbulence model.

Boundary Conditions: The boundary conditions that are applied on the model are as below:

Table 3 Bounadry conditions

\begin{tabular}{|c|c|c|c|}
\hline Specification & nati Fluid & Inlet temp & $\begin{array}{c}\text { Mass Flow } \\
\text { rate }\end{array}$ \\
\hline Cold fluid(tube side) $\mathbf{m}_{\mathbf{c}}$ & Water- $\mathrm{Al}_{2} \mathrm{O}_{3} \mathrm{el}$ & $303 \mathrm{~K}$ & $0.09 \mathrm{~kg} / \mathrm{s}$ \\
\hline Hot fluid(shell side) $\mathbf{m}_{\mathbf{h}}$ & $\begin{array}{l}\text { Water } \\
\text { evelopr }\end{array}$ & $363 \mathrm{~K}$ & $0.61 \mathrm{~kg} / \mathrm{s}$ \\
\hline
\end{tabular}

Solution and Results: After putting the boundary conditions, the solution is initialized and then iteration is applied so that the values of all parameters can be seen in a curve or line graph. After the iteration gets completed final result could be seen.

\section{RESULTS AND DISCUSSIONS}

Heat transfer through heat exchanger depends on the mass flow rate and temperature of fluid flowing inside the heat exchanger. In current flow rate of $0.09 \mathrm{Kg} / \mathrm{s}$ of cold fluid and $0.61 \mathrm{Kg} / \mathrm{s}$ of hot fluid have been considered. Fins are provided on the tube is kept triangular to maximize the area of heat transfer. To analyze the cumulative effect of nanofluid and fins on the heat exchanger rate, the CFD model of heat exchanger has been developed. The main purpose of the present work is obtaining the maximum value of heat transfer rate by improving the overall heat transfer coefficient. That can be calculated by using formula written below:

$\mathrm{Q}=\mathrm{UA} \boldsymbol{\theta}_{\mathrm{m}} \times$ No. of tubes

Where, $Q=$ Heat transfer rate in watt

$A=$ Surface Area in square meter

$\boldsymbol{\theta}_{\mathrm{m}}=\mathrm{LMTD}$ in kelvin

$\mathrm{U}=$ Overall heat transfer coefficient

After validation of the CFD model of the heat exchanger, five different mass flow rate of nanofluid is allowed to flow through the heat exchanger with fin and without fin at its tube and the results are summarized with the 
help of, line graph and table. The results obtained from the formulation of this problem are discussed in this chapter and the contours of temperature and pressure difference are shown.
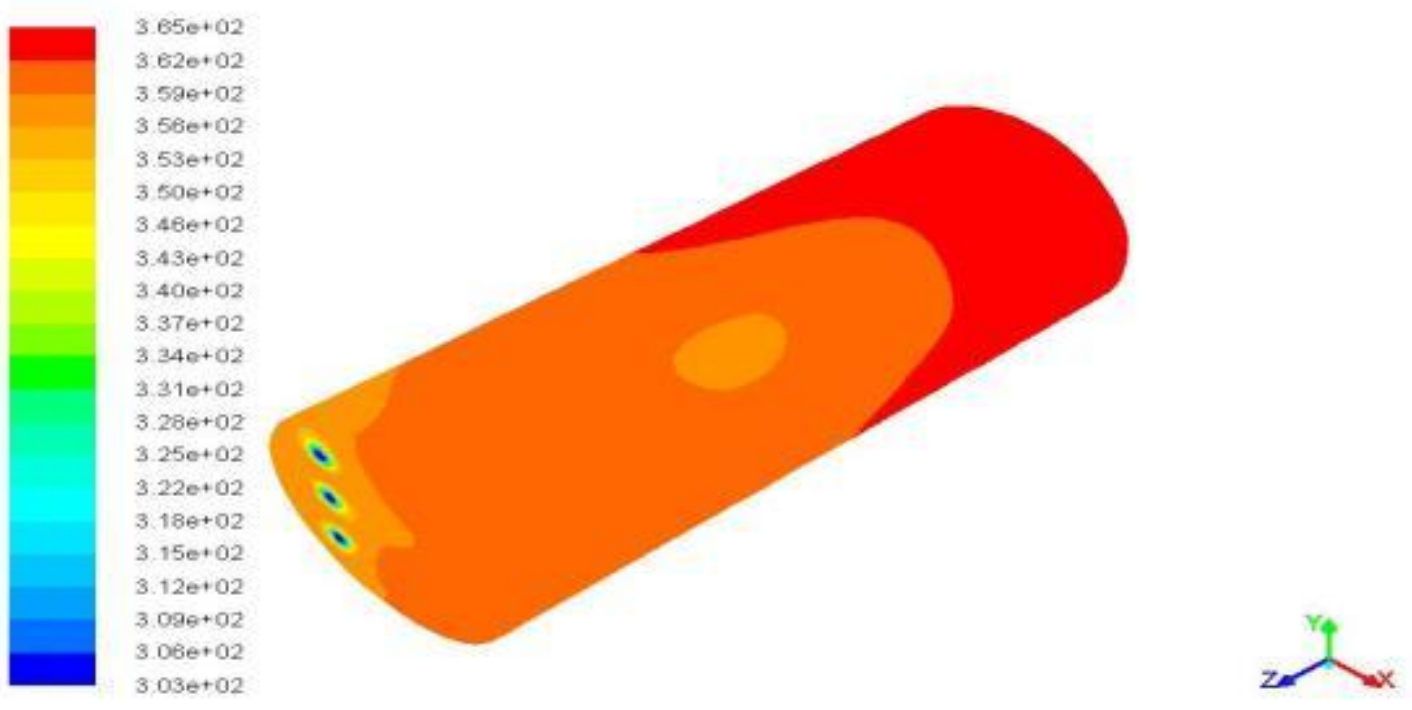

Fig.4 Contours of Temperature variation on shell side

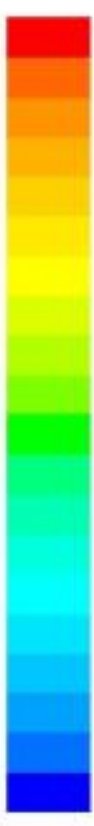

Fig.5 Contours of temperature variation on tube side 



Fig.6 Contours of Pressure variation on shell side

The temperature variations obtained from CFD results are mentioned below:

Cold Fluid inlet $=303 \mathrm{k}$,

Cold Fluid outlet $=359.26 \mathrm{k}$

Hot Fluid inlet $=363 \mathrm{k}$

Hot Fluid outlet $=355.4 \mathrm{k}$

Table 4: Comparison of overall heat transfer coefficient and Nusselt number of CFD simulated results from previous value.

\begin{tabular}{|c|c|c|c|}
\hline $\begin{array}{c}\text { Physical } \\
\text { property }\end{array}$ & $\begin{array}{c}\text { AL2O3-Water } \\
\text { nanofluid as a } \\
\text { cooling medium at } \\
\text { Pe=60000, 2\% } \\
\text { volume fraction }\end{array}$ & $\begin{array}{c}\text { AL2O3-Water } \\
\text { nanofluid as a } \\
\text { cooling medium } \\
\text { with triangular fin } \\
\text { at Pe }=\mathbf{6 0 0 0 0 , 2 \%} \\
\text { volume fraction }\end{array}$ & \% Enhancement \\
\hline $\begin{array}{c}\text { Overall heat } \\
\text { transfer coefficient } \\
\text { U (W/sq. meter } \mathrm{k})\end{array}$ & 356.2 & 373.73 & $4.77 \%$ \\
\hline Nusselt number & 77 & 81.21 & $5.46 \%$ \\
\hline
\end{tabular}




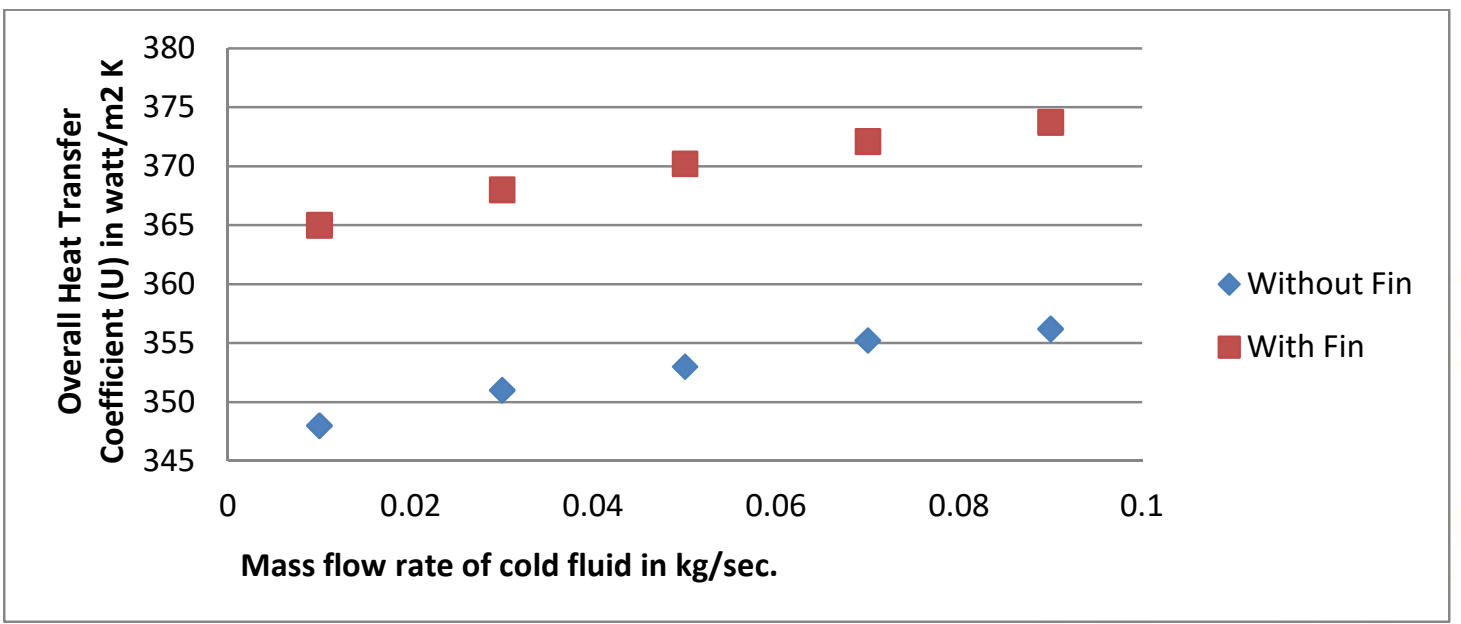

Fig.7: Variation of overall heat transfer coefficient with respect to mass flow rate of cold fluid.

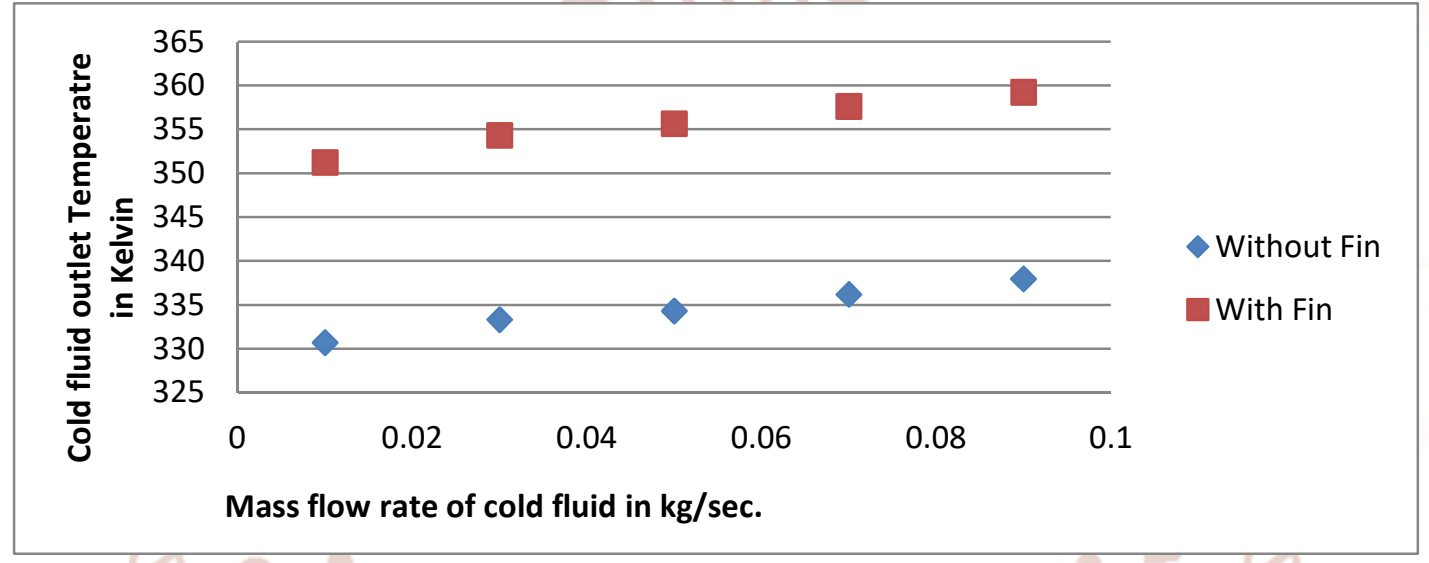

Fig.:8 Variation of cold fluid outlet temperature with respect to the mass flow rate of cold fluid

The above figure shows that the value of outlet temperature of cold fluid increases with mass flow rate of cold fluid using triangular fin and found to be maximum at $0.09 \mathrm{~kg} / \mathrm{sec}$ mass rate of cold fluid. The value of Outlet Temperature of cold fluid prominently increases with the use of triangular fin.

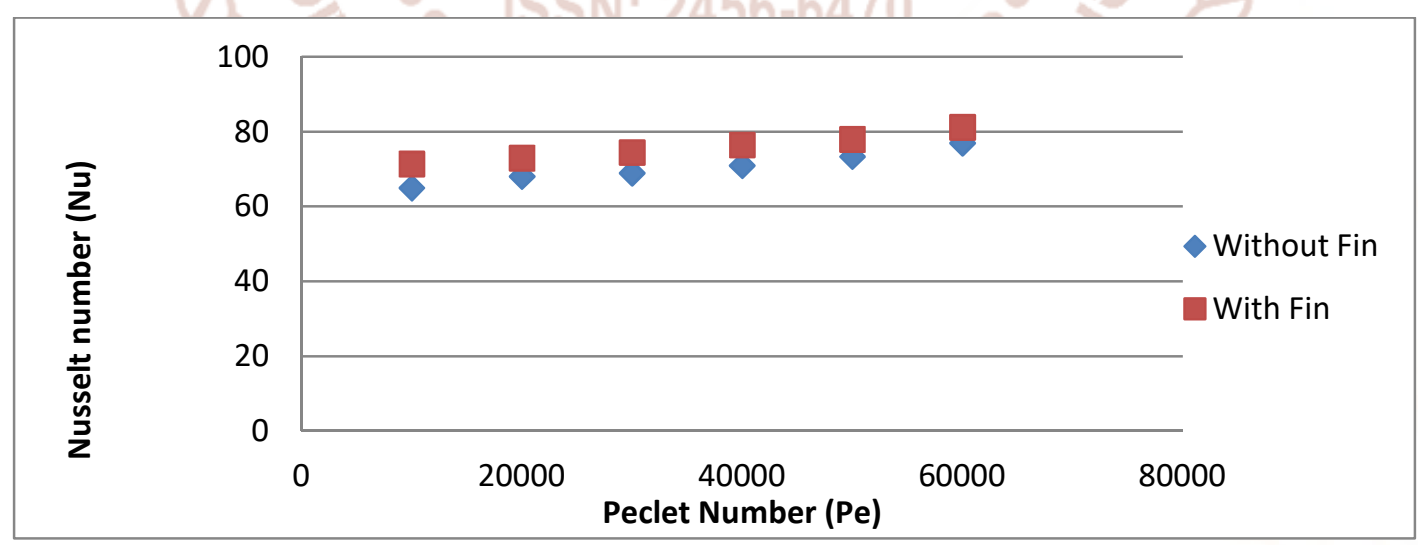

Figure 9: Variation of Nusselt number with respect to Peclet number

The above figure shows that the value of Nusselt number of cold fluid increases with Peclet number using triangular fin and found to be maximum at $\mathrm{Pe}=$ 60000. The value of Nusselt number of cold fluid prominently increases with use of triangular fin.

\section{CONCLUSIONS}

In this analysis, the cumulative effect on fins and nanofluid in shell and tube heat exchanger has been investigated using CFD analysis. Based on the results obtained by the CFD analysis it has been observed that at mass flow rate of cold fluid i.e. $0.09 \mathrm{Kg} / \mathrm{s}$ and hot fluid i.e. $0.68 \mathrm{Kg} / \mathrm{s}$, the overall heat transfer 
coefficient increased by $4.77 \%$ by using triangular fins and nanofluid. At mass flow rate of cold fluid i.e. $0.09 \mathrm{Kg} / \mathrm{s}$ and hot fluid i.e. $0.68 \mathrm{Kg} / \mathrm{s}$, the outlet temperature of cold fluid increased by 14 Kelvin by using triangular fins and nanofluid. Figures shows that over all heat transfer comparison for overall heat transfer coefficient, which confirms that net heat transfer is maximum when fins and nanofluid is used together.

Optimum utilization of energy, the equipment used in industries, must be efficient .By using shell and tube heat exchanger with a nanofluid and fins along tubes, heat transfer from the system can be increased to a great extent. The works that can be done in future are use different materials of the tube and shell for analysis, Injection of air bubbles can further add to heat transfer rate and use different combination Nanofluids and different shape of fin for analysis.

\section{REFERENCES}

1) J.Koo, C.Kleinstrecer, Laminar Nano fluid flow in micro heat sink. International journal of heat and mass transfer 48(2005).

2) J.Koo, C.Kleinstrecer, Laminar Nano fluid flow in micro heat sink. International journal of heat and mass transfer 48(2005).

3) Shung-Wei Kang, Wei-Chiang Wei, Sheng-Hong Tsai, Shih-Yu YANG, Experimental investigation of silver Nano fluid on heat pipe thermal performance, Applied thermal engineering 26(2006).

4) Shuichi Torii, Experimental study on convective heat transfer of aqueous suspension of Nano diamond particle, International symposium on Eco Topia science 07 (2007).

5) S.J.Kim, I.C. Bang, J.Buongiorno, and, and L.N.Hu, Study of pool boiling and critical heat flux enhancement in Nano fluid.bullletin of the polish academy of sciences technical science.vol55,no 2,(2007).

6) PaisarnNaphon, Pichai Assad among Kol, TeerapongBorirak, Experimental investigation of titanium Nano fluid on the heat pipe thermal efficiency, International communication in HMT 35 (2008).

7) S.H.Anil Kumar and G.Jilani, convective heat transfer enhancement in an enclosure with fin utilizing Nano fluid, International journal of aerospace and mechanical engineering.(2009)

8) www.google.com

9) Eed Abdel-Hafer ABDEL-Hadi, Sherif Handy Taher, Abdel Hamid Mohamed Torki, and Samar sabryHauad, Heat transfer analysis of vapour compression system using Nano Cuo-R134a International conference on advanced materials engineering vol. 15(2011).

10) Weer a pun Buang thong suk and SomchaiWongwises, Heat transfer enhancement and flow characteristic of alumina- water Nano fluid flowing through a micro channel heat sink. The second TSME International conference on mechanical engineering. 19-21 October( 2011).

11) Yanuar, N.Putra, GunawanS.M.Bagi, Flow and convective heat transfer characteristic of spiral pipe for Nano fluid. IJRRAS 7(3).June (2011).

12) Nawaf H. Saeid and Tan HengChaia, Investigation of thermal performance of air to water heat exchanger using Nano fluid, IIUM Engineering journal /special issue mechanical engineering, (2011).

13) E.Ebrahiminia- Bajestan, H.Niazmand, Convective heat transfer of Nano fluid flow through an isothermally heated curved pipe. Iranian journal of chemical engineering vol.8 no.2, (2011).

14) Manay E, Salein B, Yilmaz M, Gelis Thermal performance analysis of Nano fluid in micro channel heat sinks. World academy of Science, Engineering and Technology vol. 67 (2012).

15) Anchupogu Praveen, penugonda Suresh babu, Venkata Ramesh Manila, Analysis on heat transfer in Nano fluid for aluminawater.International journal of advanced scientific research and technology issue 2, volume 2(April 2012).

16) Mahdi Pirhayati, Mohamed Ali Akharan Behab adimortez akhayat, Pressure drop of Cuobase Nano fluid flow inside an inclined tube. International journal of advances in engineering and technology. November (2012).

17) Manna, S.K.Singh and G Paul, Enhanced thermal conductivity of Nano silicon carbide dispersed water based Nano fluid. Indian academy of sciences.vol 35, no 5.octobet pp.707-702 (2012). 
18) Kavitha.T,Rajendren,A,Durairajen.A,S.Syedabuth ahir. Advanced heat transfer enhancement using titanium oxide-water based Nano fluid. IJMIEVOL 2.ISSUE 4(.2012).

19) W.I.A. Aly, Numerical study on turbulent heat transfer and pressure drop of nanofluid in coiled tube-in-tube heat exchangers, Energy Convers. Manage. 86 (2014) 304- 316.Farajollahi, S.Gh. Etemad , M. Hojjat., Heat transfer characteristics of $\mathrm{Al} 2 \mathrm{O} 3 /$ water and $\mathrm{TiO} 2 /$ water nanofluids, 14(2014)489-496,23Aug 2013 @ Elsevier Ltd.

20) Shriram S. Sonawane, Rohit S. Khedkar, Kailas L. Wasewar,"Study on concentric tube exchanger heat transfer performance usingAl2O 3 - water based nanofluids", International Communications in Heat and Mass Transfer 49 (2013) 60-68@ 2013 Elsevier Ltd.

21) MM.Elias, et al. Effect of different nanoparticle shapes on shell and tube heat exchanger using different baffle angles and operated with nanofluid , science direct 70 (2014)289-297.
22) M.Bahiraei, et al. ,A novel application for energy efficiency improvement using Nanofluid in shell and tube heat exchanger equipped with helical baffles ,Science direct 93, (2015) 2229-2240

23) Davood Panahi ,et al. Heat transfer enhancement of shell-and-coiled tube heat exchanger utilizing helical wire tabulator, App. thermal engineering,(2016) 1-24.

24) Seid Mahdi Jafari,et al., Designing and application of a shell and tube heat exchanger for Nanofluids thermal processing of liquid food products, Journal of food process engineering,(2017) 1-1028.

25) K Somasekhar,et al., A CFD investigation of heat transfer enhancement in shell and tube heat exchanger using A12O3-H2O Nanofluids science direct Proceedings 5 (2018) 1057-1062 